\title{
The Method and Index of Sustainability Assessment of Infrastructure Projects Based on System Dynamics in China
}

\author{
Jun Zhou ${ }^{1}$, YingJia Liu ${ }^{2}$ \\ ${ }^{1}$ Central University of Finance and Economics (Cbina) \\ ${ }^{2}$ Graduate School of Chinese Academy of Social Sciences (China) \\ cufeshouj@126.com,yingjia.lin1991@gmail.com
}

Received: May 2015

Accepted: June 2015

\section{Abstract:}

Purpose: As one of the most important overhead capital of urban economics and social development, the sustainable development of urban infrastructure is becoming a key issue of prosperous society growing. The purpose of this paper is to establish a basic model to analysis certain infrastructure project's sustainable construction and operation.

Design/methodology/approach: System dynamics is an effective stimulation method and tool to deal with such complex, dynamics, nonlinear systems, which could be used in analyzing and evaluating all aspects of infrastructure sustainability internally and externally. In this paper, the system is divided into four subsystems and 12 main impact indicators.

Through setting the boundary and other basic hypothesis, this paper designs the basic causal loop diagrams and stock \& flow diagrams to describe the relationship between variables and establish a quantifiable structure for the system.

Findings: Adopting a sewerage treatment in China as a case to test our model, we could conclude that the model of internal sustainable subsystem is reasonable. However, this model is a basic model, and it need to be specific designed for the certain project due to the diversity of infrastructure types and the unique conditions of each projects.

Originality/value: System Dynamics (SD) is widely used in the study of sustainable development and has plentiful research achievements from macro perspective but few studies in the microcosmic project systems. This paper focuses on the unique characteristics of urban 
infrastructure in China and selects infrastructure project which is based on micro-system discussion. The model we designed has certain practical significance in policy setting, operation monitoring and adjustment of the urban projects with high rationality and accuracy.

Keywords: project evaluation, sustainability, urban infrastructure, sustainable development, system dynamics, method, model, indicators, subsystems

\section{Introduction}

Urban infrastructure is the drive of economic and social development. Different from general fixed assets, urban infrastructure has a board influence and has formed a very complicated network with various aspects in city. In China, as the foundation of urban development, the rational and effective construction and operation of urban infrastructure is of great significance. The World Bank pointed out that infrastructure stock increasing is associated with the GDP increasing, and the low utilization efficiency and downplaying the maintenance of the constructed item are common phenomena in the developing country, which means that administrators pays more attention on construction rather than operation (World Bank, 1994; World Bank, 2005).

In China, it is obvious that infrastructure construction is in a rapid progress. The amount of basic industries and infrastructure investment is 18270.3 billion RMB yuan from 2003 to 2007 combining with an annual increase rate of $24.9 \%$ (National Bureau of Statistics of China, 2008). However, the high growth is followed by a series of problems as other developing countries meet with, such as low operating efficiency, high assets depreciation rate, heavy losses, resources wasting and environment pollution. As urban roads for example, according to Code for design of urban road engineering issued by Ministry of Housing and Urban-Rural Development of the People's Republic of China (MOHURD) as a national industrial standard, the design life of urban main road cement concrete pavement is 30 years. In fact, quite a few roads damaged at the first year. As waterworks for another example, the tap water quality is suspected in several cities by news reported, which is seriously threatened human health. If those issues are beyond control, the facility itself would scrape. More seriously, due to the bad operation and low-quality products, negative effects on local economy, society and environment will occur and cannot be reserved in a long period (e.g. the outbreaks caused by contamination of domestic water could be fatal, such as Japan's Minamata disease broke out in 1950 's). Therefore, the infrastructure operation should meet the requirement of sustainability. Meanwhile, a valid scenario analysis method is important in the research of urban infrastructure sustainable construction and operation. 


\section{Literature Reviews}

\subsection{Different Aspects of Infrastructure Sustainability}

According to recent research, the infrastructure sustainability is discussed in three dimensions: economic, society and environment, so the sustainable infrastructure projects should meet the requirement in all these three dimensions (Fernández-Sánchez \& Rodríguez-López, 2010). Therefore, the methodology and indicator selection should balance those three impact parts of infrastructure project, which are of equal importance in the sustainability. But, we could find that the method of three sustainable development divisions did not pay attention to the differences between internal and external project system, which has different requirements and standard in the two sides of infrastructure sustainability.

\subsection{Analysis Method of Infrastructure Sustainability}

The meaningful analysis method is required to be consistent in time and weighted in criteria indices (Loucks, 1997). There is diversity of methodologies used in infrastructure sustainable development assessment, such as Life-Cycle Assessment (LCA), Analytic Hierarchy Process and Entropy Weights Model. As an international standard (ISO 14040), LCA wildly applies to various kinds of sustainability assessment. Many researchers think that the different methods may bring up different results. The multiple tools should be applied to an integrated comprehensive conclusion (Haimes, 1992).

However, only a few of literatures have an integral approach taking all aspects of infrastructure sustainability into account (Yigitcanlar \& Dur, 2010; Yao, Shen, Tan \& Hao, 2011), especially for the project with a long operation period and major impact (Yao et al., 2011). The fragment approaches, which solve problems separately, will generally lead to further, unexpected problems (Bohunovsky, Jäger, Omann, 2011). According to Singh, Murty, Gupta and Dikshit (2009), "sustainability is also about their inter-linkage and the dynamics developed in the system. "Hence, some tools have flaws, such as LCA, as it is generally focus on environment and not for other dimensions (Sahely, Kennedy \& Adams, 2005).

The method of System dynamics (SD) is a science that study system feedback structure and behavior. It is generally used to deal with complex, dynamics, nonlinear systems, especially in the field of society and economy. In addition, it has a tight connection to sustainable development research: Meadows, Meadows, Randers and Behrens (1972) used the SD model to establish the WORLDW Model and wrote The Limits to Growth, which triggered a worldwide discussion in sustainable development. Randers (2000) took a further step to illustrate the breakthrough in sustainable development by imitating realistic conditions using WORLDW Model. In China, several researchers using SD model to assess sustainable development on national level of energy, society and environment (Wang, Li, Wu, Ding \& Huang, 1998; Ding, Wang, Li, Wu, Yu \& Huang, 1998; Wu, Wang, Huang, Li \& Ding, 1998) and regional level 
(Wang, Yang, \& Li, 2009). SD method has been a mature scenario analysis tool in macro sustainable development analysis.

Except the application in macro level, there are only few of researches trying to apply SD model in a micro perspective, which is to conducting a single urban infrastructure's sustainable development analysis. Zhang, Wu, Shenand Skitmore (2014) uses SD principle to measure technology and people's perception's impact on construction projects' sustainability.

\subsection{Analysis Indicators of Infrastructure Sustainability}

The principles of indicator selection of sustainability assessment are robust, responsive and easy to communicate, but it is not an easy work (Gui-Torres, 2007). The International Standardization Organization proposed an indicators framework in 2006 (ISO 21929-1). Although it is for buildings originally, it is a standard pattern to guiding the indicators selection of infrastructure sustainability (Fernández-Sánchez \& Rodríguez-López, 2010). So far, most indicators in literatures are chosen by three dimensions: economy, society and environment. However, there are still existing mainly two problems. Firstly, there do not have a uniform standard (Gui-Torres, 2007) due to the diversity of projects, organizations and researches (Jones \& Silva, 2009). Secondly, it cannot get rid of subjectivity and uncertainty (Hueting \& Reijnders, 2004; Gui-Torres, 2007).

Undoubtedly the indicators selection should base on certain perspectives such as stakeholders, infrastructure types or countries and regions and it should cover the most aspects (Jones \& Silva, 2009). Levett (1998) suggest to choose policy related indicators and Andersson and Rydén (2006) consider it should be done in municipal view. Sahely et al. (2005) think different types of infrastructures should have their corresponding assessment indicators. To be particularity, Ye (2009), Ugwu, Kumaraswamy, Wong and Ng (2006) and Shen, Wu and Zhang (2011) study the indicator choosing for China. Hence, to enhance the accuracy of stimulation, we have to limit the applied range of urban infrastructure for model establishment. As a consequence, the system dynamics model designed in this paper focuses on single infrastructure project's operation in the micro perspective of sustainability in China with multidimensions including internal and external divisions.

\section{Analysis and Assessment Framework of Infrastructure Sustainability}

The analysis framework should contain external and internal sustainability in a single infrastructure project. Firstly, as a kind of special economic product, an infrastructure project could give influence on its service region to some extent, which depends on its type and size. Secondly, its sustainable level is equal important due to the extensive investment, lower income and longer payback period. In addition, the project itself is inevitably affected by 
external environment, so both external and internal sustainability should be put into a whole system to analyze.

\subsection{Sustainability of Internal Projects}

The internal sustainability of a certain infrastructure project is to longer its operation life and to minimize adverse impacts without disturbing basic requirement such as demand satisfying and products quality. There are four aspects should be focused: First, meet the requirement of green operation. The specific requirements include pollutants treatment, environmental friendly materials utilization, disaster prevention capability and employee's health and safety. Second, realize the conveniently updated and maintained of the facility. It means to reach a relative high-level in facilities and technology under resource constraints without ignoring the maintainability of facilities and updateability of materials, functions and structure. Third, control the cost in operation. It is because that infrastructure is constructed for public welfare rather than profits, which is different from general fixed assets. Last, achieving valid management, which is using scientific manage methods to minimize risk and maximize efficiency in production due to its strong local influence.

\subsection{Sustainability of External Projects}

The external sustainable development of a certain infrastructure is to increase its positive externality and decrease negative externality. It is generally discussed in three parts: economy, society as well as environment.

The infrastructure sustainability is mainly influencing economy in two ways, including local economic amount and structure. The infrastructure projects and products can be an input to facilitate economy growth directly and through scale effect by gathering variable infrastructure to stimulate economy growth indirectly. In addition, infrastructure is proved to have spillover effect as it can improve other input factors' production efficiency (Liu, 2011). In structure aspect, investment in certain kinds of infrastructure can reflect the local industrial policy and motivate industrial transformation.

The social impacts of the infrastructure projects are shown in two sides. On the one side, it satisfies human's basic urban living requirement and even improve their living quality. Residents can benefit it from the service it provides and the job opportunity it creates, which builds relationship with economy. On the other side, it could threaten human health and safety such as the roads which do not equipped with security facilities, etc.

The environmental impact is diverse due to the different infrastructure types. Some types of infrastructure consume energy greatly, such as public transportation. Some could result in severe environment contamination, such as energy supply projects. According to existing research result, the pollution from infrastructure is severer than other industry (Sahely et al., 
2005). Nevertheless, some infrastructure is constructed to curb environmental pollution, such as sewage and refuse treatment plant. No matter positive or negative side it may cause, the implication on resources and environment would be enormous, because infrastructure is general in large scale and have strong productivity.

In summary, the three aspects mentioned above would imply internal sustainable development of infrastructure projects as shown in Figure 1.

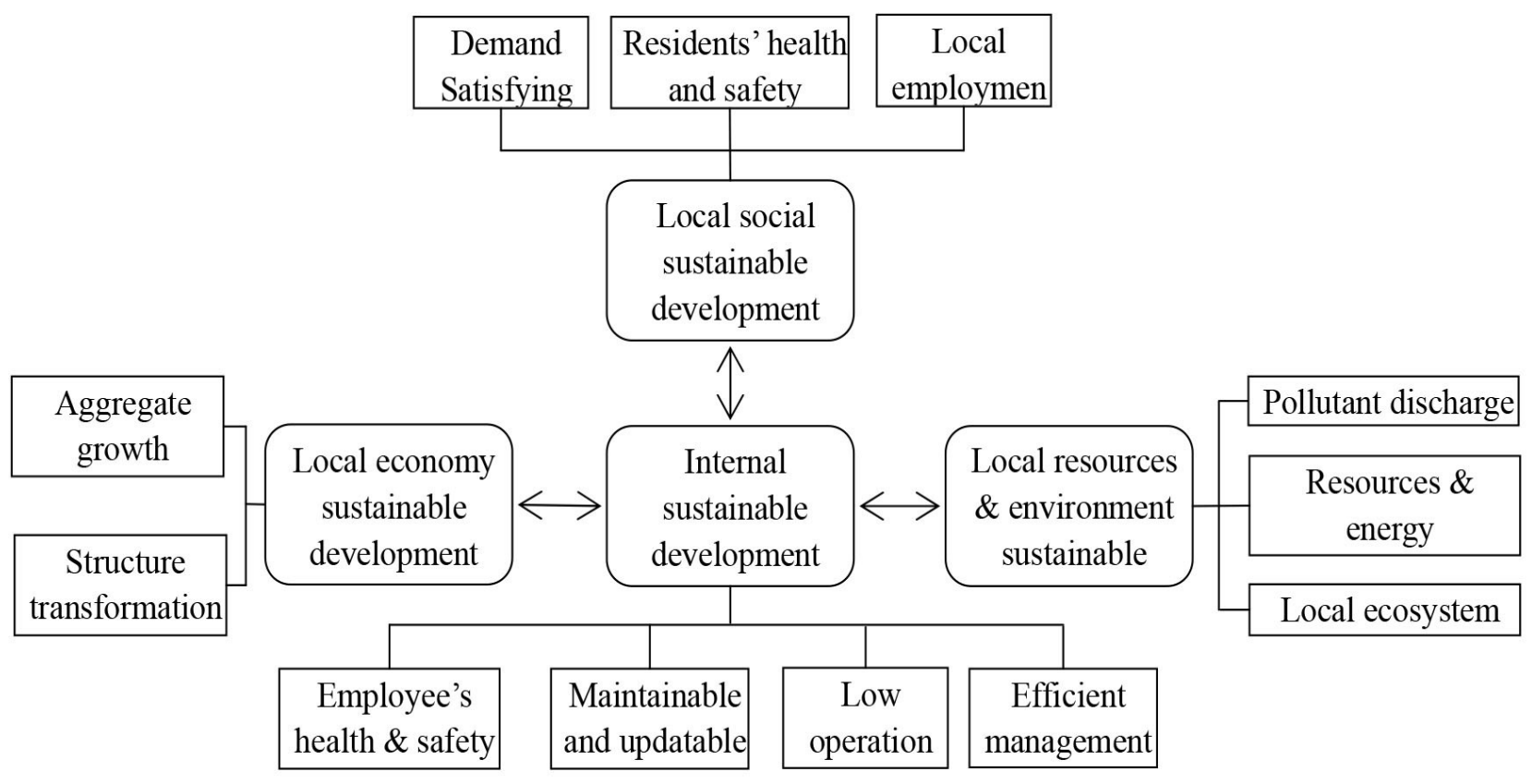

Figure 1. Analysis diagram of infrastructure sustainability

\section{The Method and Index System of Sustainability Assessment of Infrastructure Project}

\subsection{Model Hypothesis}

It is because the system dynamics method is a combination of quantitative and qualitative analysis that the modeling of the same issue by different people or different view could result in the diversity of the model. The system dynamics science regards that the model is a relative result under the preset requirement and condition. Consequently, in this paper, we regard system dynamics as a kind of scenario simulation and policy analysis tool, which is inevitable in subjectivity. And our design cannot fit the actual situation accurately. Even though, it still has a value in systematic logical thinking and policy analysis. The basic hypothesis in this paper is as follow. 


\subsubsection{Application Stage}

There are six stages in infrastructure sustainable development construction: sustainable planning, sustainable design, sustainable purchase, sustainable construction, sustainable operation and ultimate disposal. Above all, the sustainable design and sustainable operation are critical in those stages. In the stage of design, it is essential to project management in terms of sustainability consequences of the future implemented assets and products (Labuschagne \& Brent, 2005). In the stage of operation, because of the uncertainty and cumulative effect emerging in long-term operation, we should forecast potential problems through past data. In addition, due to the characteristics of the system dynamics, the research object should have a long running period. As a result, the model designed in this paper is applied in the stage of sustainable design and operation, and the application object is the project's operation system. Although the focus in two stages is different, we could establish the same model to meet different requirements because they share the same indicator system.

\subsubsection{Application Type}

The system dynamics model is vary due to the diversity of infrastructure types and operation patterns. The model demonstrated here is mainly focus on the infrastructure projects which operation is similar with industrial enterprises; including water supply plants, sewage and refuses treatment plants and so on. As a result, the indicators we choose are generalizability and the model we design is basic and differences weakened. Moreover, the indicators related to science and technology is not including in our model on account of discrepancy, which could not conclude to a single standard in our basic model. Therefore, it should be accurate design in the specific project.

\subsubsection{Model Boundary}

The boundary displayed below (Figure 2) is a summary and refining from several literatures (Ye, 2009; Ugwu et al., 2006; Shen et al., 2010) and has been divided into four section corresponding to four subsystems. The selected indicators are from the perspective of infrastructure itself. The key indicators in each subsystem are corresponding to the framework displayed in Figure 1. The indicators inside the oval are the main endogenous variable and the others are main exogenous variables.

Moreover, out of the high government participation (most of the urban infrastructure is constructed and invested by government), combining its characteristics as public goods, the majority of projects should under the government regulation. As a result, we assume that the price and operation mode are steady in a long period. In addition, to simplified model, we do not consider lag-out. 


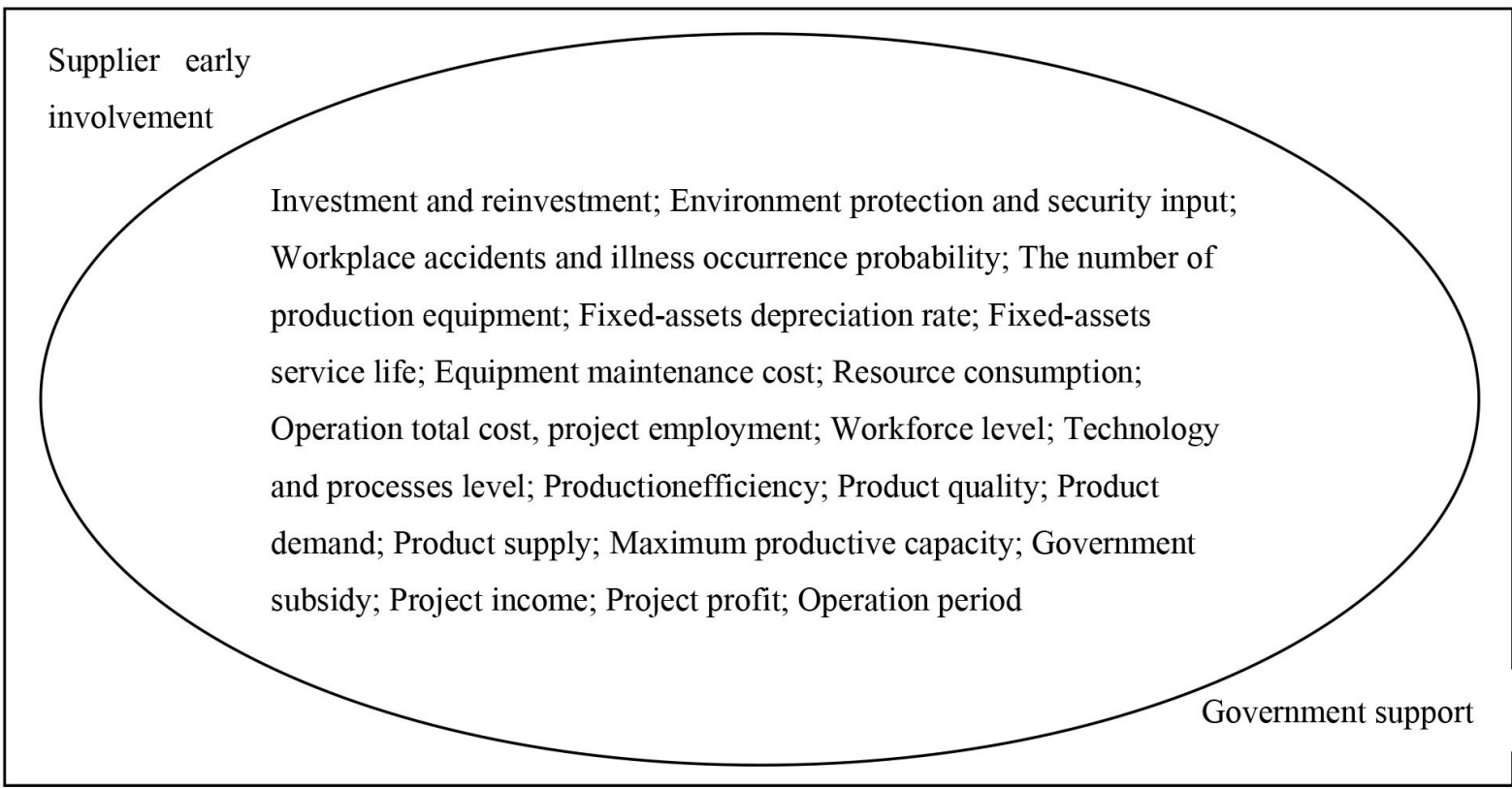

(a) Internal urban infrastructure sustainable development subsystem

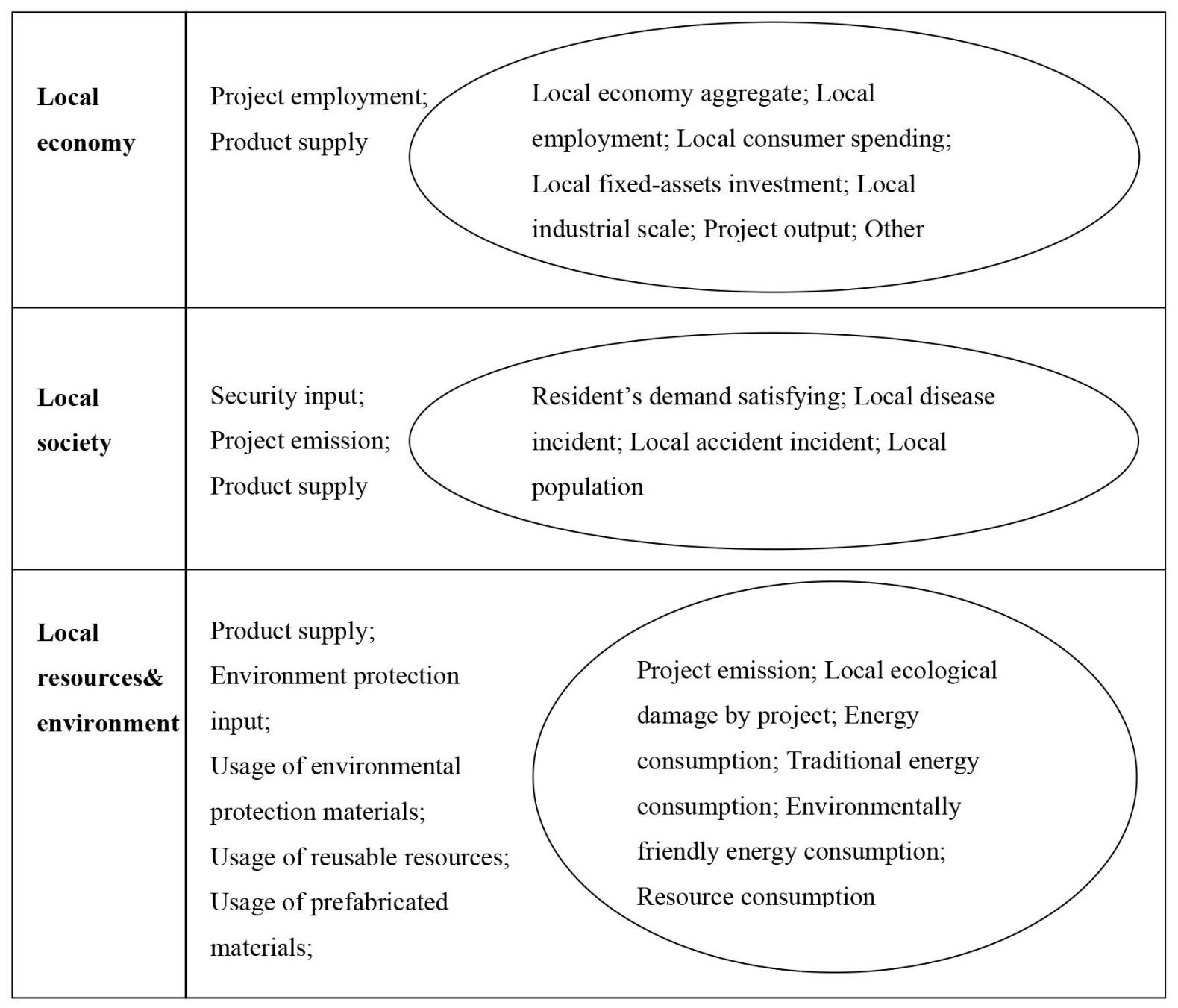

(b) External urban infrastructure sustainable development subsystem.

Figure 2. Boundary of four subsystems of dynamic model in sustainable infrastructure system 


\subsection{The Causal Loop Diagrams of the Four Subsystems}

\subsubsection{The Causal Structure between the Subsystems}

An urban infrastructure project's sustainable development system dynamics model consists of four subsystems. From the view of causality, the internal subsystem is the core and the operation strategy decides itself sustainable development. Meanwhile, the project's operation strategy could impose on its service region through economy, society and resources \&environment, which is another aspect to reflect its sustainable development by externality. In addition, the external environment will react to the project to some degree. To sum up, there are feedback loops between those four subsystems.

Theoretically, there are second even more order's causality relationships between the three external subsystems. To simplify the model, we just take into account the population and employment between society and economy and residents' health and pollution between society and resources \&environment (Figure 3).

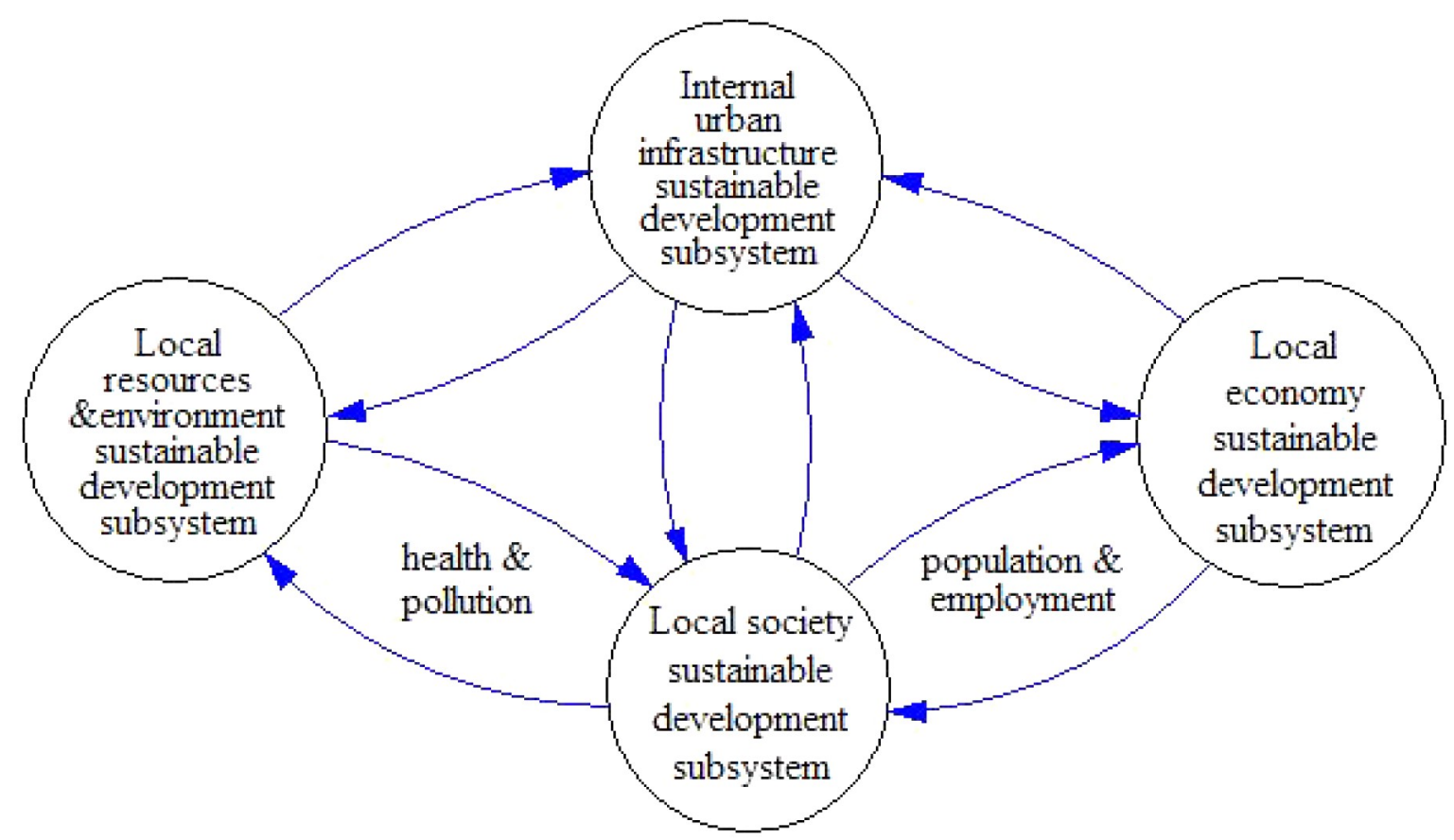

Figure 3. The causality between four urban infrastructure sustainable development subsystems 


\subsubsection{The External Causal Structure of Subsystems}

The causal loop diagrams of four subsystems is as follow (Figure 4).

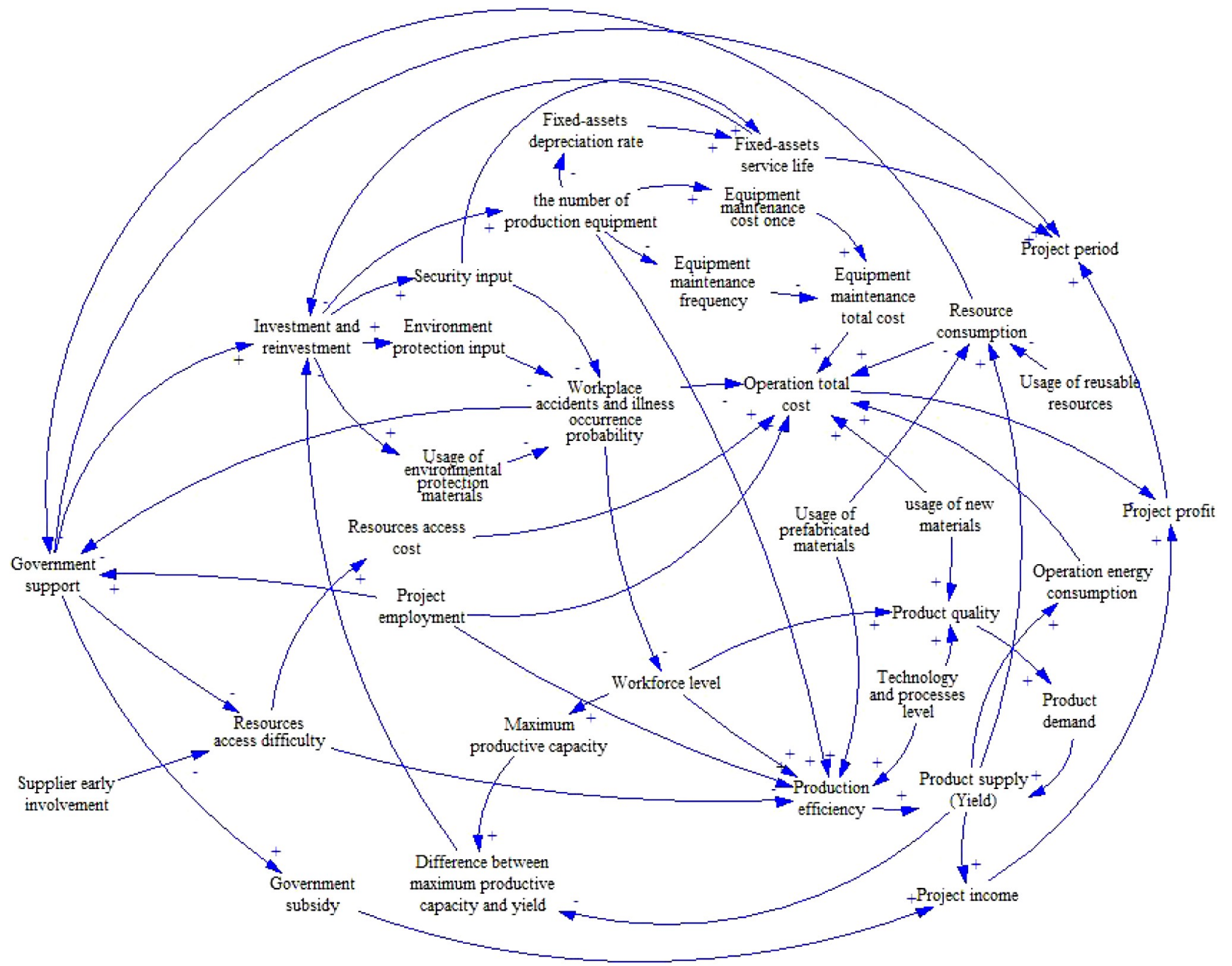

(a) Internal sustainable urban infrastructure system

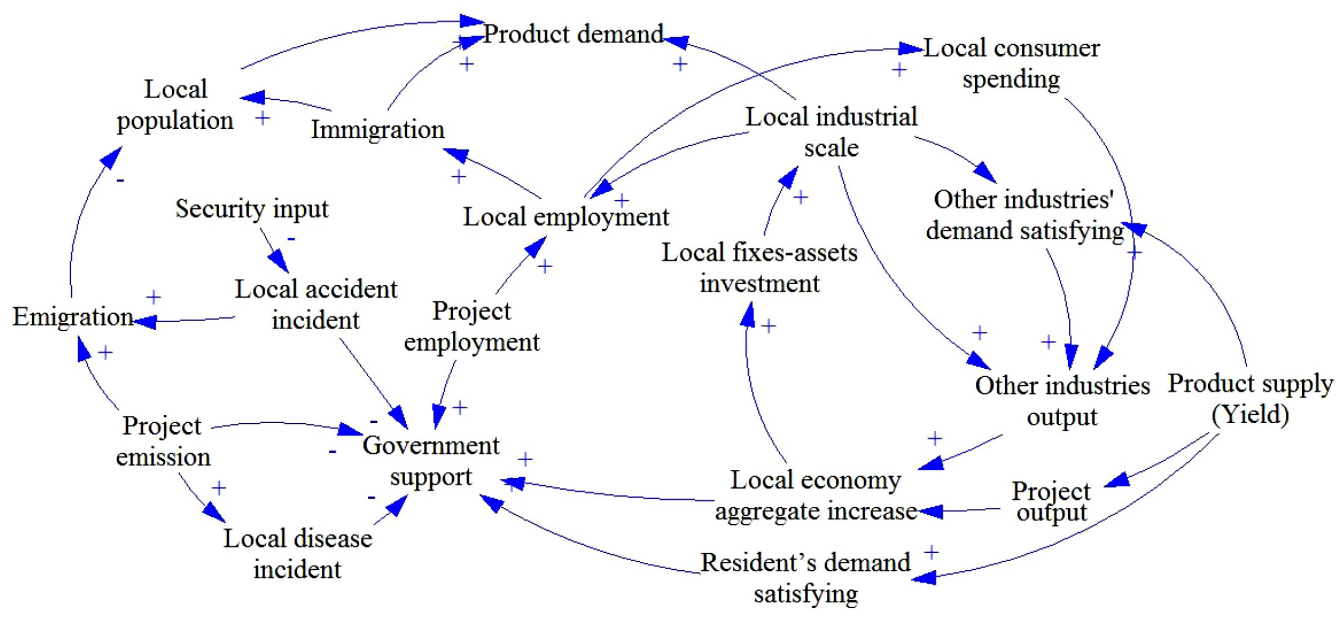

(b) Local economy \&society sustainable development 


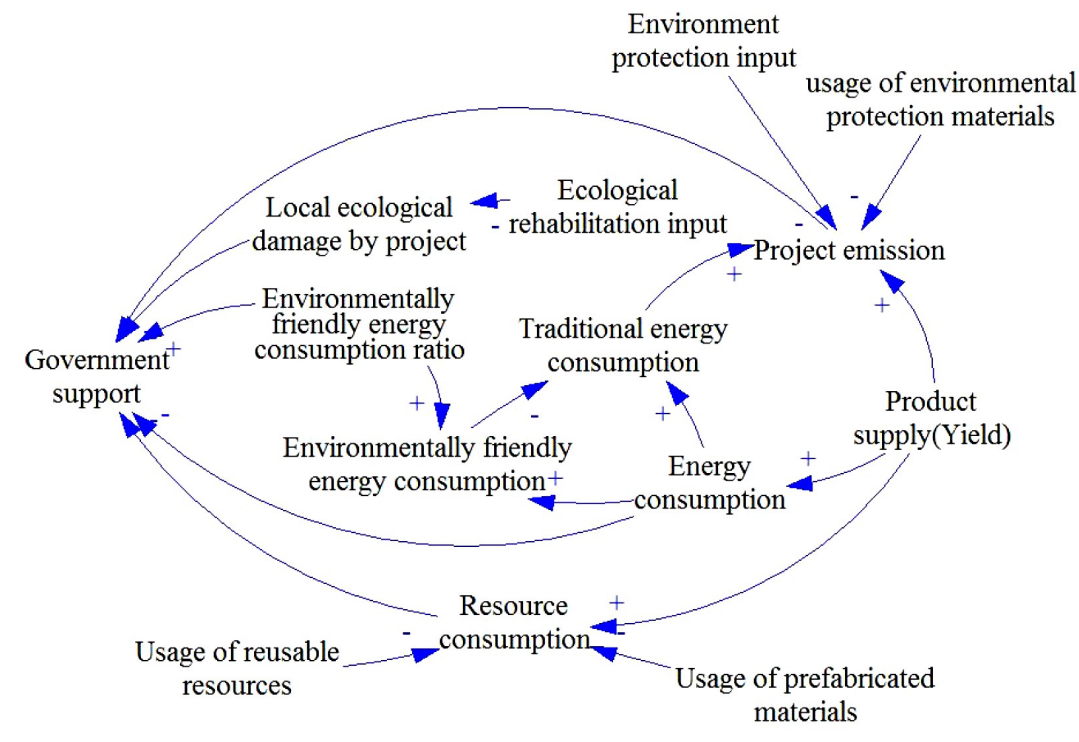

(c) Local resources \&environment sustainable development

Figure 4. The causal loop diagrams of four subsystems

There are 34 endogenous and exogenous variables in the Figure 4(a). To illustrate, the core financial indicator of the infrastructure project should be operation total cost, however, the determining factors of the project period are still be net cash flow and profit. We choose profit here for the sake of simplify. Because the infrastructure is non-rivalry public goods, the yield is restricted by demand. As a result, we assume the yield is equal to sales.

There are 34 endogenous and exogenous variables in Figure 4(b). Due to the close relationship between economy and society subsystems, we put these two parts into one diagram to demonstrate.

There are 14 endogenous and exogenous variables in Figure 4(a). In this part, we just consider the adverse impact on local resources and environment. The opposite effects by some kinds of infrastructure, such as sewage treatment plant, which is to help ease environment issues, could be regarded as its products included in internal subsystem.

The integrity diagram which includes four subsystems' causal loop diagrams is displayed in Figure 5. 


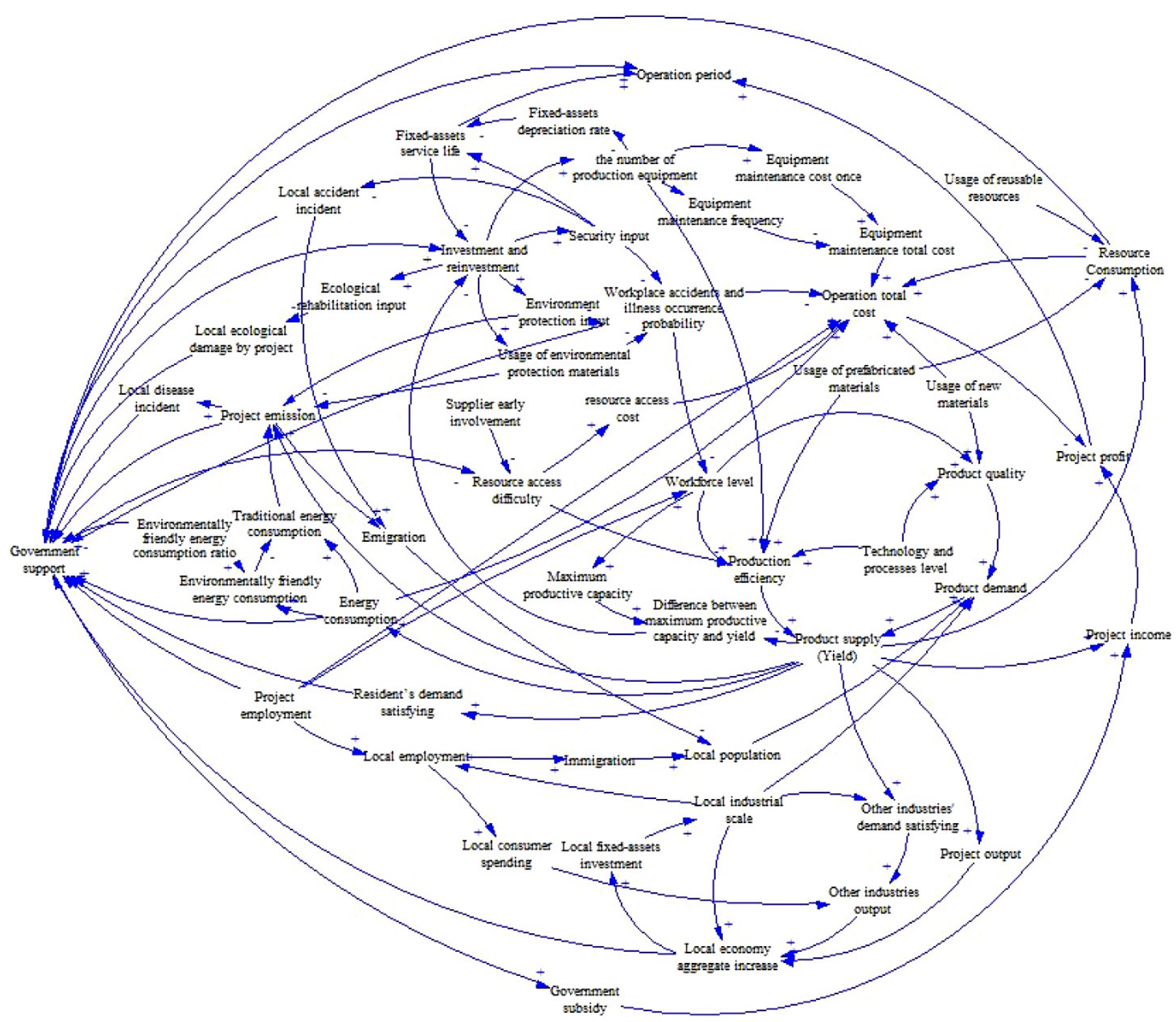

Figure 5. The integrity causal loop diagrams of the model

\subsection{The stock and flow diagram of the system}

The structure of the sustainable urban infrastructure development is explained by stock and flow diagrams. Based on this diagram, we could quantify the model through state equation and rate equation. It could be used to scenario analysis and policy choice.

The state variables in the diagram should be meaningful stock variables.

A general form of the state equation is:

$$
L . K=L . J+\left(R_{i} . J K-R_{2} . J K\right) \times D T
$$

Among above, $\mathrm{L}$ is the state variable, $\mathrm{R} 1$ and $\mathrm{R} 2$ are input and output variables respectively. DT is step and $\mathrm{J}, \mathrm{K}$ are the beginning and ending time-point of the calculation period.

Rate variables are calculated by auxiliary variables and constants through rate equation. The structure may need to adjust to fit a certain project. 
The integrity diagram which includes four subsystems' stock and flow diagrams is as follow (Figure 6).

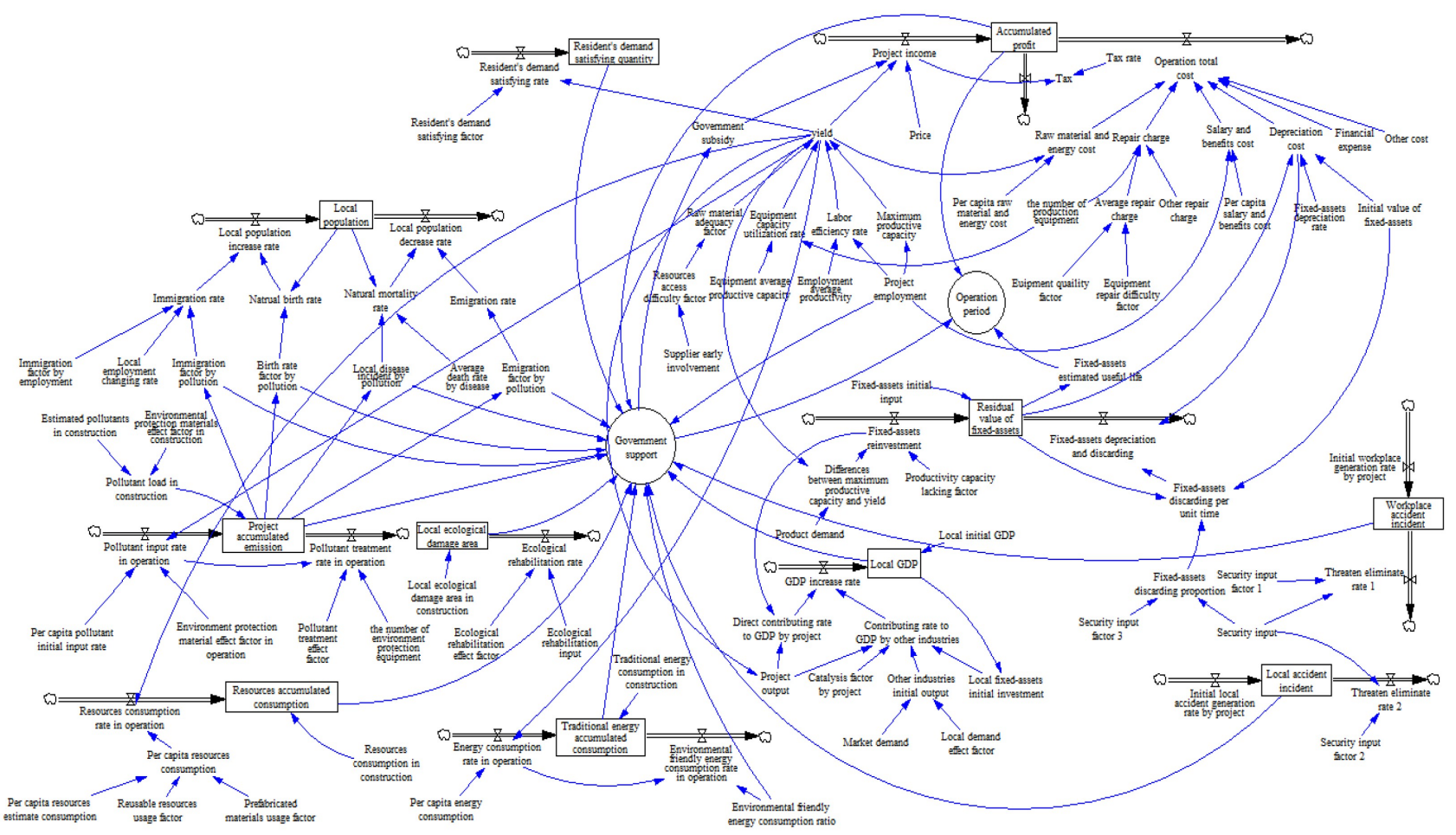

Figure 6. The integrity stock and flow diagrams of the model

\section{A Case Analysis}

We choose sewerage treatment plant $A$ as a case to test the model of internal sustainable development subsystem illustrated above. The state variables are accumulated profit and fixed-asset residue value.

The sewerage treatment plant $A$ is in the north of the town, which located in southeast coast in China. The designed daily processing capacity is 10,000 tons/ day and the price is steady at 1.75 yuan $/ \mathrm{m} 3$. The planed ramp up time and full production time is 2 years and 16 years respectively. The relevant date and information derive from the feasibility study report of sewerage treatment plant $A$.

In this case, we add interest of loan and business tariff and annex as the rate variables to meet the peculiarity.

\subsection{Dimensionally Homogeneous Test}

The software we used named Vensim, which has the function to test equation and dimensionally homogeneous. The system does not hint error while running, therefore, the model pass the dimensionally homogeneous test. 


\subsection{Mental Stimulation Test}

Establishing equations and inputting data then running the model, we obtain some variables' result, which depicts in Figure 7.

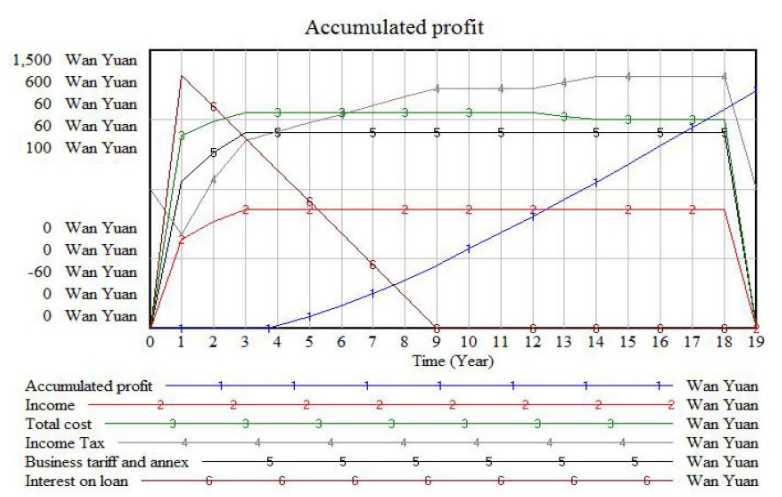

(a)

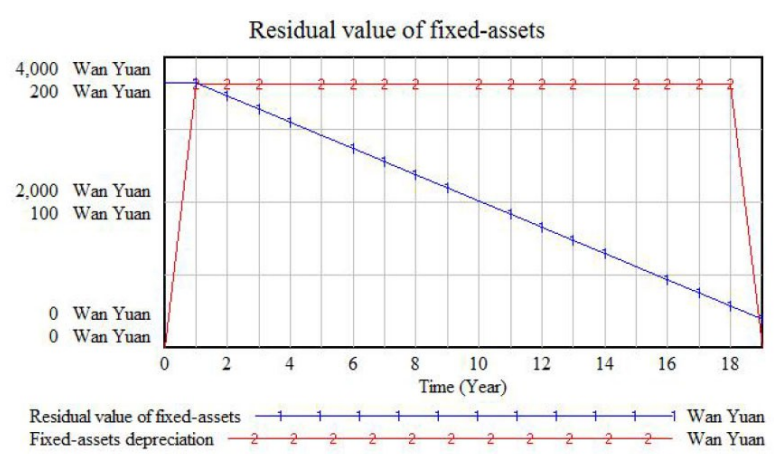

(b)

Figure 7. The result of mental test.

(a) The test result of accumulated profit and related rate variables;

(b) The test result of residual value of fixed-assets and related rate variables. The unit wan yuan in the graph is 10,000 yuan

The current data reflects the rate variables' effect in the last phase, as a result, the accumulated profit and fixed-asset residue value will has a one year lag. The relationships between variables are certain and steady, which the running result is accurate matching the data in the feasibility study report. The test result could prove that the model in this part is reliable.

\subsection{Sensitivity test}

We increase and decrease $10 \%$ of the price and per capita raw material and energy cost respectively to test the changing in accumulated profit (non-discount). The result is showed in Table 1 and Figure 8.

The results demonstrate that price impact more on accumulated profit than the per capita raw material and energy cost. Therefore, a reasonable sewerage treatment price is vital to this case. 


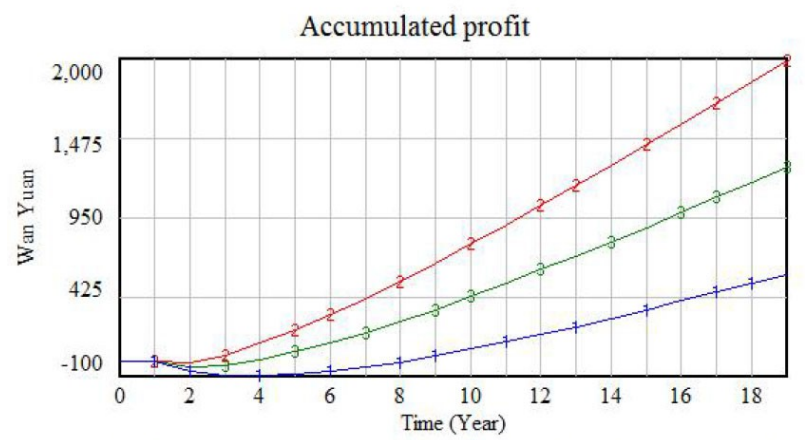

Accumulated profit : Price- $10 \%$

Accumulated profit : Price $+10 \%$

Accumulated profit : Current

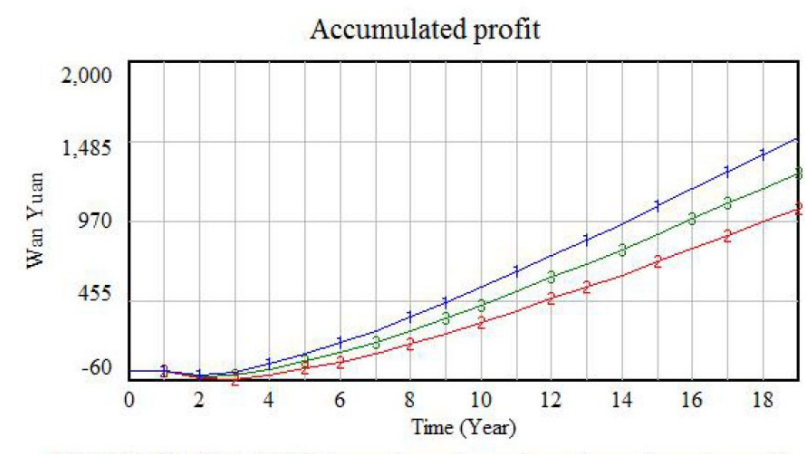

Accumulated profit : cost- $10 \%$

Accumulated profit : $\cos t+10 \%$

Accumulated profit : Current

(a)

(b)

Figure 8. Result of sensitivity test.

(a) The influence on accumulated profit by price;

(b) The influence on accumulated profit by per capita raw material and energy cost

\begin{tabular}{|l|c|c|c|c|c|}
\hline Item & Current & \multicolumn{2}{|c|}{ Price } & \multicolumn{2}{c|}{ Per capita raw material and energy cost } \\
\hline Variation range & 0 & $+10 \%$ & $-10 \%$ & $+10 \%$ & $-10 \%$ \\
\hline The final accumulated profit & 1279 & 1985 & 574 & 1048 & 1510 \\
\hline Sensitivity coefficient & & 5.52 & 5.52 & -1.81 & -1.81 \\
\hline
\end{tabular}

Table 1. Result of sensitivity test

\section{Conclusions}

Through the analysis of urban infrastructure sustainable development's influential factors and their causal association, we design a basic system dynamic model in a micro view. The model is mainly used in sustainable design (support to decide the key attributes) and sustainable operation (to help policy adjustment). The applicable urban infrastructure type is which operation is similar to industrial enterprises.

At present, there only a few of the studies focus on system dynamics simulation of micro infrastructure individual sustainable development. This paper is a preliminary attempt. Therefore, there are some aspects that need further exploration.

Firstly, the whole system stimulation requires very detailed data.Due to the limited data, we could only test two of the state variables in the stock\& flow diagram. As a result, the causal loop diagram and the stock \& flow diagram we designed might have following defects: unreasonable model boundary, no causal relations in some variables, cannot pass the mental test in some parts.

Secondly, do not design specific model for different types. Due to the diversity of the urban infrastructure types and the technology knowledge defect in a certain project, we ignored 
technology and just designed a general applicable model. For this reason, to dealing with a certain project in given type and location, the variables and structure need adjusted.

\section{Acknowledgements}

This research project (Grant No. 71372192) was supported by National Natural Science Foundation of China.

\section{References}

Andersson, M., \& Rydén, L. (2006). The project portfolio approach to urban sustainability management. Material for the Sustainment workshop in Riga, 30 October-2 November.

Bohunovsky, L., Jäger, J., \& Omann, I. (2011). Participatory scenario development for integrated sustainability assessment. Regional Environmental Change, 11(2), 271-284. http://dx.doi.org/10.1007/s10113-010-0143-3

Ding, F., Wang, Y., Li, S.Y., Wu, Y.J., Yu, S.X., \& Huang, Z.Z. (1998). A system dynamics simulation model for the sustainable development of China - Environmental sector. Computer Simulation, 1, 8-10.

Fernández-Sánchez, G., \& Rodríguez-López, F. (2010). A methodology to identify sustainability indicators in construction project management-Application to infrastructure projects in Spain. Ecological Indicators, 10(6), 1193-1201. http://dx.doi.org/10.1016/j.ecolind.2010.04.009

Gui-Torres, D. (2007). Sustainability indicators and the assessment of urban water systems: Seeking for a robust way forward. Young Scientific Workshop: Urban Water Innovation. April. Delft University of Technology, Netherlands.

Haimes, Y.Y. (1992). Sustainable development: a holistic approach to natural resource management. Systems, Man and Cybernetics, IEEE Transactions on, 22(3), 413-417. http://dx.doi.org/10.1109/21.155942

Hueting, R., \& Reijnders, L. (2004). Broad sustainability contra sustainability: the proper construction of sustainability indicators. Ecological economics, 50(3), 249-260. http://dx.doi.org/10.1016/j.ecolecon.2004.03.031

ISO21929-1. (2006). Sustainability in Building Construction - Sustainability Indicators - Part 1: Framework for the Development of Indicators and a Core Set of Indicators for Buildings. International Organization for Standardization.

IS014040. (2006). Environmental Management - Life Cycle Assessment-Principles and Framework. International Organization for Standardization.

Jones, S.A., \& Silva, C. (2009). A practical method to evaluate the sustainability of rural water and sanitation infrastructure systems in developing countries. Desalination, 248(1), 500-509. http://dx.doi.org/10.1016/j.desal.2008.05.094 
Labuschagne, C., \& Brent, A.C. (2005). Sustainable project life cycle management: the need to integrate life cycles in the manufacturing sector. International Journal of Project Management, 23(2), 159-168. http://dx.doi.org/10.1016/j.ijproman.2004.06.003

Levett, R. (1998). Sustainability indicators-integrating quality of life and environmental protection. Journal of the Royal Statistical Society: Series A (Statistics in Society), 161(3), 291-302. http://dx.doi.org/10.1111/1467-985X.00109

Liu, S.L. (2011). Infrastructure and Economic Development. Beijing: Tsinghua University Press. Loucks, D.P. (1997). Quantifying trends in system sustainability. Hydrological Sciences Journal, 42(4), 513-530.http://dx.doi.org/10.1080/02626669709492051

Meadows, D.H., Meadows, D.L., Randers, J., \& Behrens, W.W. (1972). The limits to growth. New York, 102.

National Bureau of Statistics of China, (2008). The report of three decades reform and opening-up - part 4: Great achievement in basic industry and infrastructure construction. National Bureau of Statistics of China.

Randers, J. (2000). From limits to growth to sustainable development or SD (sustainable development) in a SD (system dynamics) perspective. System Dynamics Review, 16(3), 213-224.

Sahely, H.R., Kennedy, C.A., \& Adams, B.J. (2005). Developing sustainability criteria for urban infrastructure systems. Canadian Journal of Civil Engineering, 32(1), 72-85.

Shen, L., Wu, Y., \& Zhang, X. (2010). Key assessment indicators for the sustainability of infrastructure projects. Journal of construction engineering and management, 137(6), 441-451. http://dx.doi.org/10.1061/(ASCE)CO.1943-7862.0000315

Singh, R.K., Murty, H.R., Gupta, S.K., \& Dikshit, A.K. (2009). An overview of sustainability assessment methodologies. Ecological indicators, 9(2), 189-212.

http://dx.doi.org/10.1016/j.ecolind.2008.05.011

Ugwu, O.O., Kumaraswamy, M.M., Wong, A., \& Ng, S.T. (2006). Sustainability appraisal in infrastructure projects (SUSAIP): Part 1. Development of indicators and computational methods. Automation in construction, 15(2), 239-251. http://dx.doi.org/10.1016/j.autcon.2005.05.006

Guangjing, W., Jijun, Y., \& Qingfei, L. (2009). System Dynamic Model for Sustainable Development of Regional Economy and Its Application. Reformation \& Strategy, 1, 040.

Wang, Y., Li, S.Y., Wu, Y.J., Ding, F., \& Huang, Z.Z. (1998). A system dynamics simulation model for the sustainable development of China: Social sector. Computer Simulation, 15(1), 5-7.

Wang, G.J., Yang, J.J., \& Li, Q.F. (2009). System Dynamic Model for Sustainable Development of Regional Economy and Its Application. Reformation \& Strategy, 1, 040. 
World Bank Staff. (1994). World development report 1994: Infrastructure for development. Oxford University Press, Incorporated.

World Bank Staff. (2005). World development report 2005: A better investment climate for everyone. Oxford University Press, Incorporated.

Wu, Y.J., Wang, Y., Huang, Z.Z., Li, S.Y., \& Ding, F. (1998). A system dynamics simulation model for the sustainable development of China - Energy sector. Computer Simulation, 1, 1113.

Yao, H., Shen, L., Tan, Y., \& Hao, J. (2011). Simulating the impacts of policy scenarios on the sustainability performance of infrastructure projects. Automation in Construction, 20(8), 1060-1069. http://dx.doi.org/10.1016/j.autcon.2011.04.007

Ye, M. (2009). Research on the Sustainability Factors of Urban Large Infrastructures. Urban Studies, 10, 017.

Yigitcanlar, T., \& Dur, F. (2010). Developing a sustainability assessment model: the sustainable infrastructure, land-use, environment and transport model. Sustainability, 2(1), 321-340. http://dx.doi.org/10.3390/su2010321

Zhang, X., Wu, Y., Shen, L., \& Skitmore, M. (2014). A prototype system dynamic model for assessing the sustainability of construction projects. International Journal of Project Management, 32(1), 66-76. http://dx.doi.org/10.1016/j.ijproman.2013.01.009

Journal of Industrial Engineering and Management, 2015 (www.jiem.org)

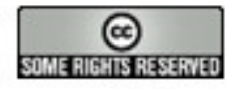

Article's contents are provided on a Attribution-Non Commercial 3.0 Creative commons license. Readers are allowed to copy, distribute and communicate article's contents, provided the author's and Journal of Industrial Engineering and Management's names are included. It must not be used for commercial purposes. To see the complete license contents, please visit http://creativecommons.org/licenses/by-nc/3.0/. 